\title{
C7 Fracture as a Complication of C7 Dome-Like Laminec- tomy : Impact on Clinical and Radiological Outcomes and Evaluation of the Risk Factors
}

\author{
Seung Heon Yang, ${ }^{1}$ Chi Heon Kim, ${ }^{1,2}$ Chang Hyun Lee, ${ }^{3}$ Young San Ko, ${ }^{1}$ Youngil Won, ${ }^{1}$ Chun Kee Chung ${ }^{1,2,4}$ \\ Department of Neurosurgery, Seoul National University Hospital, Seoul, Korea \\ Department of Neurosurgery, ${ }^{2}$ Seoul National University College of Medicine, Seoul, Korea \\ Department of Neurosurgery, ${ }^{3}$ Seoul National University Bundang Hospital, Seongnam, Korea \\ Department of Brain and Cognitive Sciences, ${ }^{4}$ Seoul National University College of Natural Sciences, Seoul, Korea
}

Objective : Cervical expansive laminoplasty is an effective surgical method to address multilevel cervical spinal stenosis. During surgery, the spinous processes of $\mathrm{C} 2$ and $\mathrm{C} 7$ are usually preserved to keep the insertion points of the cervical musculature and nuchal ligament intact. In this regard, dome-like laminectomy (undercutting of C7 lamina) instead of laminoplasty is performed on C7 in selected cases. However, resection of the lamina can weaken the C7 lamina, and stress fractures may occur, but this complication has not been characterized in the literature. The objective of the present study was to investigate the incidence and risk factors for $\mathrm{C} 7$ laminar fracture after $\mathrm{C} 7$ dome-like laminectomy and its impact on clinical and radiological outcomes.

Methods : Patients who underwent cervical open-door laminoplasty combined with C7 dome-like laminectomy $(\mathrm{n}=123)$ were classified according to the presence of $\mathrm{C} 7$ laminar fracture. Clinical parameters (neck/arm pain score and neck disability index) and radiologic parameters (C2-7 angle, C2-7 sagittal vertical axis, and C7-T1 angle) were compared between the groups preoperatively and at postoperatively at 3, 6, 12, and 24 months. Risk factors for complications were evaluated, and a formula estimating $\mathrm{C} 7$ fracture risk was suggested.

Results : C7 lamina fracture occurred in 32/123 (26\%) patients and occurred at the bilateral isthmus in 29 patients and at the spinolaminar junction in three patients. All fractures appeared on X-ray within 3 months postoperatively, but patients did not present any neurological deterioration. The fracture spontaneously healed in 27/32 (84\%) patients at 1 year and in 29/32 (91\%) at 2 years. During follow-up, clinical outcomes were not significantly different between the groups. However, patients with $\mathrm{C} 7$ fractures showed a more lordotic $\mathrm{C} 2-7$ angle and kyphotic C7-T1 angle than patients without C7 fractures. C7 fracture was significantly associated with the extent of bone removal. By incorporating significant factors, the probability of $\mathrm{C} 7$ laminar fracture could be assessed with the formula 'Risk score $=1.08 \times$ depth $(\%)+1.03 \times$ length $(\%$, of the posterior height of $C 7$ vertebral body)', and a cut-off value of $167.9 \%$ demonstrated a sensitivity of $90.3 \%$ and a specificity of $65.1 \%$ (area under the curve, 0.81 ).

Conclusion : C7 laminar fracture can occur after C7 dome-like laminectomy when a substantial amount of lamina is resected. Although C7 fractures may not cause deleterious clinical outcomes, they can lead to an unharmonized cervical curvature. The chance of $\mathrm{C} 7$ fracture should be discussed in the shared decision-making process.

Key Words : Laminoplasty · Adverse effect · Spinal stenosis, Cervical · Frature, C7 · Risk factors.

- Received : January 28, 2021 •Revised : April 1, 2021 •Accepted : May 21, 2021

- Address for reprints : Chun Kee Chung

Department of Neurosurgery, Seoul National University College of Medicine, 101 Daehak-ro, Jongno-gu, Seoul 03080, Korea

Tel : +82-2-2072-2352, Fax : +82-2-744-8459, E-mail : chungc@snu.ac.kr, ORCID : https://orcid.org/0000-0003-3485-2327

This is an Open Access article distributed under the terms of the Creative Commons Attribution Non-Commercial License (http://creativecommons.org/licenses/by-nc/4.0) which permits unrestricted non-commercial use, distribution, and reproduction in any medium, provided the original work is properly cited. 


\section{INTRODUCTION}

Cervical expansive laminoplasty is one of the surgical methods to treat cervical stenosis caused by cervical spondylotic myelopathy (CSM) or ossified posterior longitudinal ligament (OPLL). During surgery, cervical paraspinal muscles and the nuchal ligament are dissected away from their insertion at the subaxial spine (C3-C6), and the geometry of the cervical lamina is changed for decompression. Posterior elements of the C2 and $\mathrm{C} 7$ vertebrae are known to be critical structures for maintaining cervical lordosis, as they provide insertion points to extensor muscles and the nuchal ligament ${ }^{4,10,11,15,17,19,21)}$. Loss of cervical lordosis seemed to be correlated with neck pain or poor outcomes, and laminoplasty is usually performed between C3 and $\mathrm{C}^{5}$. However, spinal stenosis often develops to the $\mathrm{C} 6-7$ level and necessitates laminoplasty down to C7. Hosono et al. ${ }^{5}$ previously reported increased axial neck pain with laminoplasty extending to the $\mathrm{C} 7$ level. Because of the concern of losing insertion points at the spinous process and lamina of $\mathrm{C}$, which is detrimental to cervical lordosis, the surgical technique of partial resection and undercutting of the cranial lamina of C7 (C7 dome-like laminectomy) was introduced. By performing C7 dome-like laminectomy, most of the insertion points for muscles and ligaments could have been preserved ${ }^{5,8)}$. The efficacy and safety of C7 dome-like laminectomy have been reported, but potential complications have not been underscored $^{8)}$. We noticed unexpected fractures of the C7 lamina during follow-up after uneventful C7 dome-like laminectomy, but this has not been characterized in the literature. Thus, the objective of the present study was to investigate the incidence and risk factors for $\mathrm{C} 7$ laminar fracture after $\mathrm{C} 7$ dome-like laminectomy and its impact on clinical and radiological outcomes.

\section{MATERIALS AND METHODS}

\section{Patients}

This study was approved by the Institutional Review Board of Seoul National University Hospital (IRB No. H-1910-0211067). A retrospective cohort study was designed with consecutive patients who underwent open-door laminoplasty in the subaxial cervical spine and dome-like laminectomy at C7 between March 2015 and December 2018. Patients whose follow- up was less than 6 months were excluded from the analysis. Among the patients who underwent $\mathrm{C} 7$ dome-like laminectomy, a total of 123 patients were ultimately evaluated. According to the presence of $\mathrm{C} 7$ fractures in the follow-up images, the patients were classified into two groups ( $\mathrm{C} 7$ fracture group vs. no fracture group). The presence of $\mathrm{C} 7$ fracture was confirmed using computed tomography (CT) scan, which was taken at postoperative 6 or 12 months. If a disruption of cortical bone continuity or callus formation was seen, it was defined that there was a fracture (Fig. 1). The timing of the occurrence of $\mathrm{C} 7$ fracture was determined using postoperative $\mathrm{X}$-ray images by observing fracture line at $\mathrm{C} 7 \mathrm{isthmus}$ or comparing the relative position of the $\mathrm{C} 7$ spinous tip to the adjacent spinous process tips.

\section{Surgical procedure}

C7 dome-like laminectomy was typically performed prior to conventional open-door laminoplasty of other cervical levels. After a midline skin incision, the nuchal ligament was separated in the midline while preserving its anchoring at the C7 spinous process. The neck muscles were dissected from the spinous process and lamina in a subperiosteal manner and bilaterally retracted. Following the completion of muscular dissection exposing the C3-6 lamina, muscles covering the cranial surface of the C7 lamina were 'partially' dissected in a subperiosteal manner to expose the uppermost part of the lamina to the width of the spinal canal. The extent of the dome-like laminectomy was preoperatively planned using magnetic resonance images and CT scans. For dome-like laminectomy, the exposed C7 lamina was drilled out as planned using a $6 \mathrm{~mm}$-sized and $4 \mathrm{~mm}$-sized burr, and the ligament flavum was resected using a 1- or 2-mm Kerrison rongeur. Then, open-door laminoplasty was performed at the other subaxial levels. The detailed procedure of the open-door laminoplasty has been well described elsewhere ${ }^{9,14)}$.

\section{Clinical and radiological outcome evaluation}

Postoperatively, patients were encouraged to ambulate with a soft neck collar. They were discharged 3 days postoperatively and were scheduled to visit the clinic 1, 3, 6, and 12 months postoperatively and yearly thereafter. All patients completed the patient-reported outcome questionnaires, which consisted of the visual analog pain score (VAS) for the neck and arm and the neck disability index (NDI) at every follow-up visit. 

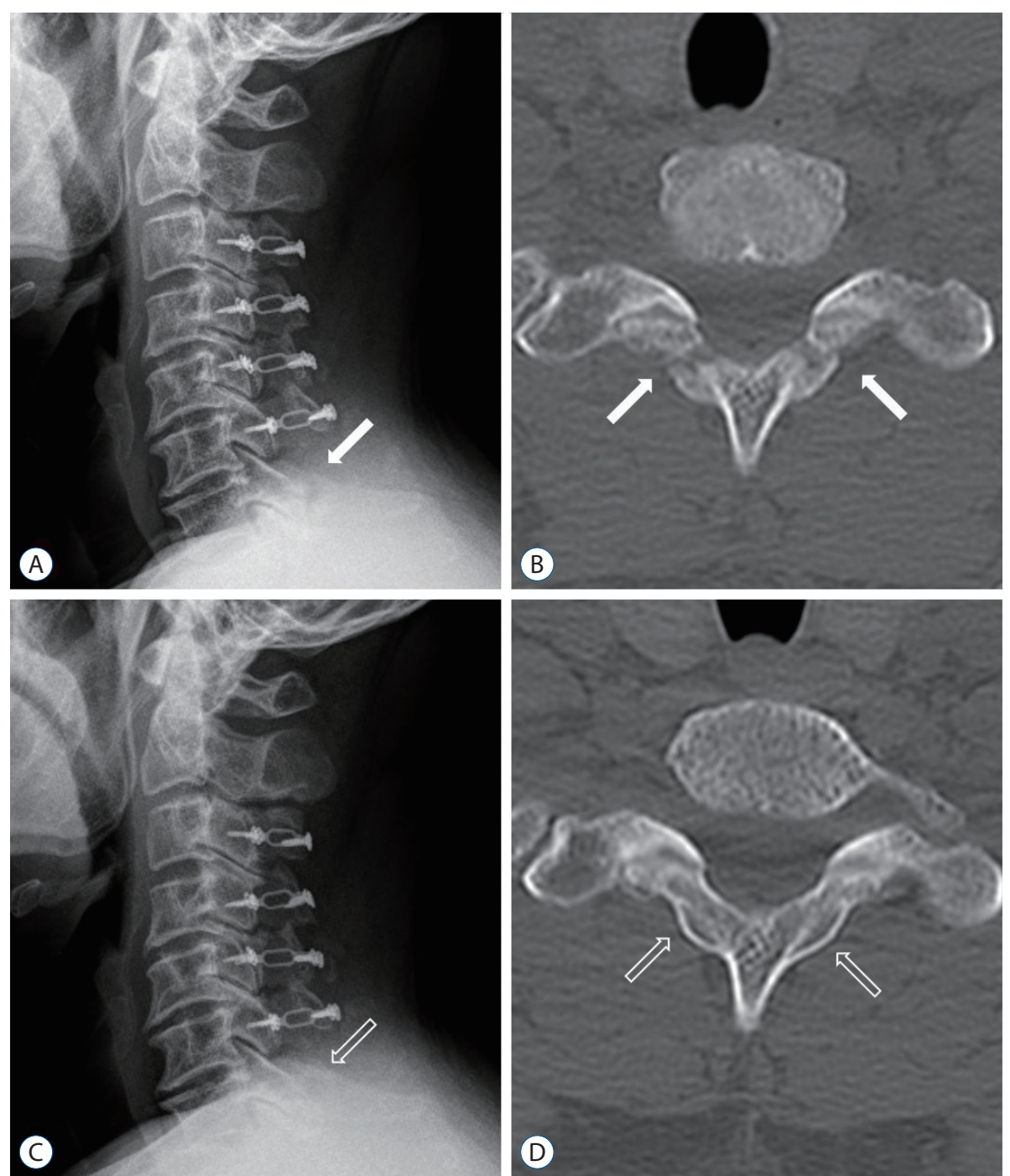

Fig. 1. Postoperative simple lateral X-ray and computed tomography (CT) scans of a 47-year-old patient who underwent C3-6 open-door laminoplasty and C7 dome-like laminectomy for cervical spondylotic myelopathy. A and B : A linear fracture line (white arrows) is seen in the lateral X-ray image taken at postoperative 3 months. This fracture, which developed along the isthmus, is also seen at a CT scan taken 6 months postoperatively. Callus formation was already visualized at the fracture sites. C and D : The fracture line is no longer visualized on postoperative 1-year images. A CT scan taken 1 year postoperatively shows complete healing of the fracture (blank arrows).

Patients routinely underwent C-spine X-rays at each visit and CT scan at 6 months postoperatively to evaluate fusion at the hinge side of the open-door laminoplasty. If the hinge side was not fused or C7 fracture was confirmed in the CT scan, a follow-up CT scan was taken at 12 months postoperatively.

For radiological outcome evaluation, we used parameters of the $\mathrm{C} 2-7$ angle, $\mathrm{C} 2-7$ sagittal vertical axis (SVA), and C7-T1 angle. The $\mathrm{C} 2-7$ angle was defined as the angle made by the lower endplate of $\mathrm{C} 2$ and the upper endplate of $\mathrm{C} 7$. The $\mathrm{C} 2-7$ SVA was defined as the distance between a plumb line dropped from the center of $\mathrm{C} 2$ and the superior-posterior cor- ner of the $\mathrm{C} 7$ vertebral body. The $\mathrm{C} 7-\mathrm{T} 1$ angle was defined as the angle made by the upper endplate of $\mathrm{C} 7$ and $\mathrm{T} 1$.

To evaluate the risk factors for $\mathrm{C} 7$ fractures, several clinical parameters, including age, sex, preoperative cervical curve type (lordotic, straight, kyphotic, and sigmoid as classified by Ishikawa et al. $\left.{ }^{7}\right)$, bone quality, and the extent of $\mathrm{C} 7$ dome-like laminoplasty, were evaluated. Bone quality was determined using the axial CT scan by measuring the Hounsfield unit because measuring bone mineral density was indicated only for women older than 65-year-old or men more than 70-year-old under the health insurance system. The cancellous bone area 
at the middle of the $\mathrm{C} 7$ vertebral body was measured using the technique described by Schreiber et al. ${ }^{18)}$ The extent of the C7 dome-like laminectomy was measured using reconstructed CT scans, .and presented in three parameters, 'width', 'length' and 'depth' (Fig. 2). The 'width' was defined as the largest width of the dome-like laminectomy, and measured from axial CT scan parallel to the $\mathrm{C} 6-7$ disc space. To measure the 'length' and 'depth', we put both pre- and post-operative midsagittal CT scans of the C7 vertebral body on the screen side to side, and delineated the extent of $\mathrm{C} 7$ dome like-laminectomy in triangular shape by comparing those images. The 'length' was defined as the length measured along the superior margin (outer cortex) of the removed lamina (the superior side of the delineated triangle). The 'depth' was defined as the length measured along the ventral margin (inner cortex) of the removed lamina (the ventral side of the delineated triangle). The measurement was performed using the integrated measurement tools of the picture achieving and communication software (Marosis; Infinitt healthcare, Seoul, Korea). Then, the measured parameters were normalized to the relative length (\%) to the posterior height of the $\mathrm{C} 7$ vertebral body since the size of vertebrae of each patient was different.

\section{Statistical analysis}

For the statistical analysis, Student's t-test, chi-square statistics, and linear by linear association were used according to the variables' characteristics. A linear mixed model (LMM) was used to compare the chronological changes in clinical and radiological parameters between the groups. The fixed effects included group, time, age, sex, preoperative cervical curve type, and group and time interactions. The random effect was the subjects. To evaluate the risk factors for $\mathrm{C} 7$ fractures, a logistic regression analysis was performed to verify independent risk factors associated with $\mathrm{C} 7$ laminar fracture. ROC curve analysis was then performed to test a formula calculating the fracture risk. All statistical analyses were performed using IBM SPSS statistics ver. 23.0 (IBM Co., Armonk, NY, USA). A $p$-value $<0.05$ was considered statistically significant.

\section{RESULTS}

The characteristics of each group are summarized in Table 1. The demographic characteristics were not significantly different between groups. There were 86 patients (69.9\%) with CSM and $37(30.1 \%)$ with OPLL, and 67.4\% (58/86) of CSM patients and $89.2 \%(33 / 37)$ of OPLL patients were male. Among a total of 123 patients, C7 fractures occurred in 32 patients (26.0\%). There was no fracture found in the immediate postoperative X-rays, but the fracture was first detected 1 month postoperatively in 26 patients (81.3\%) and 3 months postoperatively in six (19.7\%). The fracture occurred at the isthmus in $90.6 \%$ (29/32) and at the spino-laminar junction in $9.4 \%(3 / 32)$. When fracture healing was defined as the formation of bridging bone at the fracture site in either X-ray or CT scans, the cumulative fracture healing rates were $18.8 \%(6 / 32)$ at 6 months, $84.4 \%$
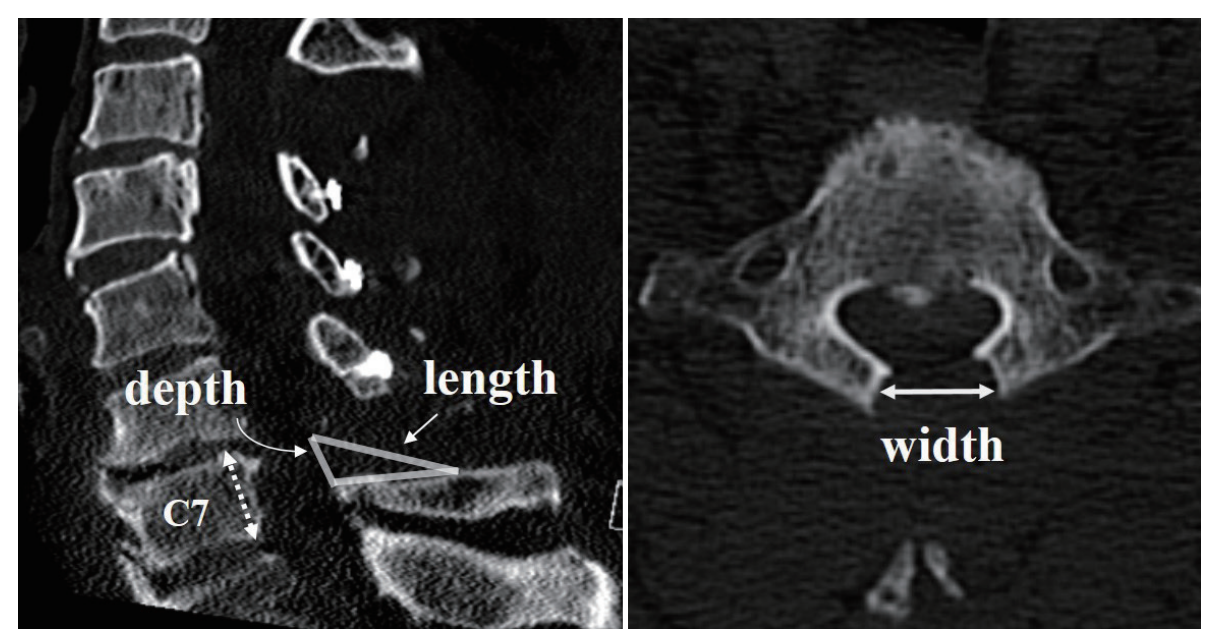

Fig. 2. The extent of C7 dome-like laminectomy was measured in three parameters (width, length, and depth) in the mid-sagittal and axial plane. Virtual line (triangle) were drawn on the postoperative computed tomography (CT) scan in comparison with preoperative CT scan to delineate the extent of $\mathrm{C} 7$ dome-like laminectomy. These parameters were standardized by dividing by the posterior height of $\mathrm{C} 7$ body (dotted line arrow). 
Complication of C7 Dome-Like Laminectomy I Yang SH, et al.

Table 1. Patient's characteristics

\begin{tabular}{|c|c|c|c|}
\hline & C7 fracture group & No fracture group & $p$-value \\
\hline No. of patient & $32(26.0)$ & $91(74.0)$ & \\
\hline Gender & & & 0.879 \\
\hline Male & $24(75.0)$ & $67(73.6)$ & \\
\hline Female & $8(25.0)$ & $24(26.4)$ & \\
\hline Age (years) & $60.91 \pm 9.13$ & $57.36 \pm 12.64$ & 0.148 \\
\hline Diagenosis & & & 0.287 \\
\hline CSM & 20 & 66 & \\
\hline OPLL & 12 & 25 & \\
\hline Curve shape, Preop. & & & $0.932^{*}$ \\
\hline Lordotic & 15 & 44 & \\
\hline Straight & 10 & 26 & \\
\hline Kyphotic & 3 & 11 & \\
\hline Sigmoid & 4 & 10 & \\
\hline \multicolumn{4}{|l|}{ Laminoplasty level } \\
\hline$C 2-6^{\dagger}$ & 4 & 4 & \\
\hline C3-6 & 20 & 65 & \\
\hline C4-6 & 8 & 16 & \\
\hline C5-6 & 0 & 6 & \\
\hline Bone quality (Hounsfield unit) & $284.3 \pm 93.8$ & $300.4 \pm 75.5$ & 0.334 \\
\hline \multicolumn{4}{|c|}{ Extent of $\mathrm{C} 7$ dome-like laminectomy $(\%)^{\ddagger}$} \\
\hline Depth & $65.1 \pm 12.0$ & $50.7 \pm 13.3$ & $<0.001$ \\
\hline Length & $114.8 \pm 22.3$ & $92.6 \pm 25.9$ & $<0.001$ \\
\hline Width & $89.9 \pm 16.0$ & $85.4 \pm 12.2$ & 0.173 \\
\hline \multicolumn{4}{|l|}{ Fracture site } \\
\hline Isthmus & $29(90.7)$ & & \\
\hline Spinous process & $3(9.3)$ & & \\
\hline
\end{tabular}

Values are presented as mean \pm standard deviation or number (\%). ${ }^{*}$ Calculated by linear by linear association. ${ }^{\dagger}$ Under-cutting was performed for C2 instead of C2 laminectomy or open-door laminoplasty. ${ }^{\ddagger}$ Extent of C7 dome-like laminectomy was presented in \% compared to the posterior height of C7 vertebral body. CSM : cervical spondylotic myelopathy, OPLL : ossified posterior longitudinal ligament, Preop. : preoperative
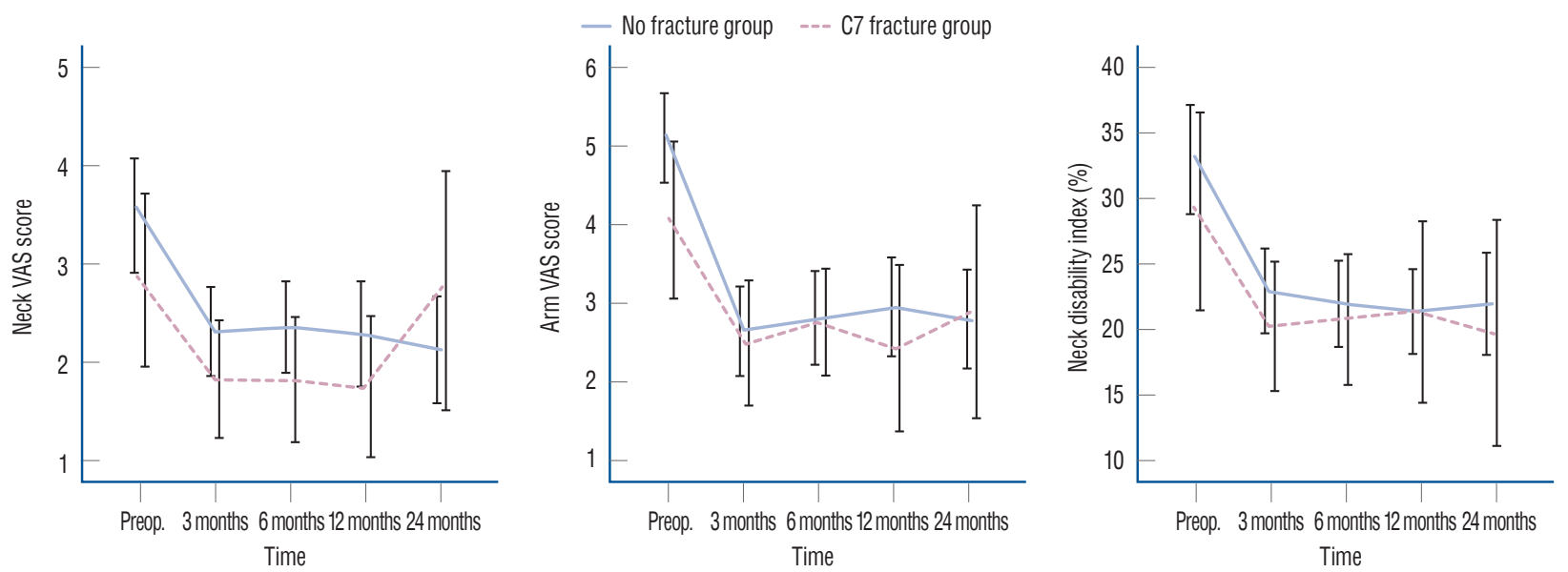

Fig. 3. Plots showing the changes in clinical outcome parameters pre- and postoperatively. There was no significant difference between the groups at each time point or over time. VAS : visual analog scale, Preop. : preoperative. 
Table 2. Radiological parameters at each time point

\begin{tabular}{|c|c|c|c|c|c|c|c|c|c|}
\hline & \multicolumn{3}{|c|}{ Neck VAS } & \multicolumn{3}{|c|}{ Arm VAS } & \multicolumn{3}{|c|}{ NDI } \\
\hline & $\begin{array}{c}\text { No fracture } \\
\text { group }\end{array}$ & $\begin{array}{l}\text { C7 fracture } \\
\text { group }\end{array}$ & $p$-value & $\begin{array}{c}\text { No fracture } \\
\text { group }\end{array}$ & $\begin{array}{l}\text { C7 fracture } \\
\text { group }\end{array}$ & $p$-value & $\begin{array}{c}\text { No fracture } \\
\text { group }\end{array}$ & $\begin{array}{c}\text { C7 fracture } \\
\text { group }\end{array}$ & $p$-value \\
\hline Preop. & $3.50 \pm 2.80$ & $2.84 \pm 2.46$ & 0.244 & $5.10 \pm 2.72$ & $4.06 \pm 2.78$ & 0.068 & $32.99 \pm 19.66$ & $29.06 \pm 21.12$ & 0.346 \\
\hline 3 months & $2.32 \pm 1.96$ & $1.83 \pm 1.60$ & 0.236 & $2.66 \pm 2.43$ & $2.50 \pm 2.16$ & 0.758 & $22.95 \pm 14.25$ & $20.27 \pm 13.34$ & 0.376 \\
\hline 6 months & $2.37 \pm 2.06$ & $1.83 \pm 1.67$ & 0.208 & $2.82 \pm 2.70$ & $2.76 \pm 1.81$ & 0.906 & $22.02 \pm 15.25$ & $20.83 \pm 13.26$ & 0.708 \\
\hline 12 months & $2.29 \pm 2.09$ & $1.76 \pm 1.74$ & 0.266 & $2.95 \pm 2.50$ & $2.44 \pm 2.58$ & 0.394 & $21.44 \pm 14.17$ & $21.39 \pm 17.17$ & 0.987 \\
\hline 24 months & $2.13 \pm 2.10$ & $2.74 \pm 2.51$ & 0.299 & $2.80 \pm 2.48$ & $2.89 \pm 2.83$ & 0.892 & $22.00 \pm 15.72$ & $19.79 \pm 17.91$ & 0.604 \\
\hline
\end{tabular}

Values are presented as mean \pm standard deviation. VAS : visual analog pain scale, NDI : neck disability index, Preop. : preoperative

Table 3. Clinical and radiological paremeters at each time point

\begin{tabular}{|c|c|c|c|c|c|c|c|c|c|}
\hline & \multicolumn{3}{|c|}{ C2-7 angle } & \multicolumn{3}{|c|}{ C2-7 SVA } & \multicolumn{3}{|c|}{ C7-T1 angle } \\
\hline & $\begin{array}{c}\text { No fracture } \\
\text { group }\end{array}$ & $\begin{array}{l}\text { C7 fracture } \\
\text { group }\end{array}$ & $p$-value & $\begin{array}{c}\text { No fracture } \\
\text { group }\end{array}$ & $\begin{array}{l}\text { C7 fracture } \\
\text { group }\end{array}$ & $p$-value & $\begin{array}{c}\text { No fracture } \\
\text { group }\end{array}$ & $\begin{array}{l}\text { C7 fracture } \\
\text { group }\end{array}$ & $p$-value \\
\hline Preop. & $-8.58 \pm 9.25$ & $-10.28 \pm 9.51$ & 0.378 & $22.84 \pm 13.08$ & $22.93 \pm 13.68$ & 0.974 & $-4.45 \pm 3.54$ & $-4.80 \pm 2.43$ & 0.682 \\
\hline 3 months & $-5.77 \pm 10.69$ & $-10.80 \pm 9.46$ & 0.026 & $23.05 \pm 14.65$ & $27.18 \pm 12.85$ & 0.177 & $-5.25 \pm 3.25$ & $-2.47 \pm 2.90$ & 0.003 \\
\hline 6 months & $-6.22 \pm 10.52$ & $-11.21 \pm 9.33$ & 0.027 & $22.53 \pm 14.12$ & $23.82 \pm 12.10$ & 0.667 & $-4.75 \pm 3.20$ & $-2.65 \pm 3.65$ & 0.046 \\
\hline 12 months & $-4.74 \pm 9.09$ & $-10.65 \pm 9.06$ & 0.007 & $24.93 \pm 12.32$ & $24.17 \pm 10.50$ & 0.787 & $-4.72 \pm 3.29$ & $-3.01 \pm 2.92$ & 0.075 \\
\hline 24 months & $-4.28 \pm 9.99$ & $-8.57 \pm 7.13$ & 0.090 & $26.45 \pm 14.74$ & $26.87 \pm 12.21$ & 0.912 & $-4.72 \pm 3.89$ & $-1.95 \pm 4.12$ & 0.052 \\
\hline
\end{tabular}

Values are presented as mean \pm standard deviation. SVA : sagittal vertical axis, Preop. : preoperative

(27/32) at 12 months, and 90.6\% (29/32) at 2 years postoperatively. No patients in the fracture group complained of neurological deterioration, and no additional surgery was required during the follow-up period.

\section{Clinical outcome}

Clinical improvements were commonly observed postoperatively in both groups (Fig. 3). The neck VAS score decreased postoperatively, and there was no significant difference between the groups at each time point. Although the neck VAS score increased at 24 months postoperatively in the C7 fracture group, the difference was not statistically significant. LMM analysis also showed no differences $(p=0.104)$ between the groups. The arm VAS score also decreased postoperatively and was maintained throughout the follow-up period in both groups. There were no significant differences in chronological changes $(p=0.118)$ or at each time point between the groups. The NDI score also decreased in both groups after surgery, and there was no significant difference in chronological changes $(p=0.100)$ or at each time point between groups. Detailed parameters were presented in Table 2 .

\section{Radiological outcome}

Radiological outcomes are summarized in Table 3. The C2-7 angle of each group changed in different ways postoperatively. The C2-7 angle became more lordotic in the C7 fracture group, and this difference was maintained throughout the follow-up period. The differences were significant at each time point except 24 months postoperatively ( $p=0.051$ ). LMM analysis also showed a significant difference between the groups. A similar result was also observed in the C7-T1 angle. The C7 fracture group lost lordosis at the C7-T1 angle, especially at 3 and 6 months postoperatively, and showed significantly higher cervical lordosis at the same time points. LMM analysis revealed a significant difference in chronological changes between groups $(p=0.007)$, and the difference was significant at postoperative 3- and 6-month ( $p=0.007$ ) (Fig. 4). Although it did not meet statistical significance, the probability value remained low even at postoperative 1-year $(p=0.075)$ and 2-year ( $p=0.052$ ). Unlike other parameters, the C2-7 SVA did not show any differences between the groups throughout the follow-up period. 

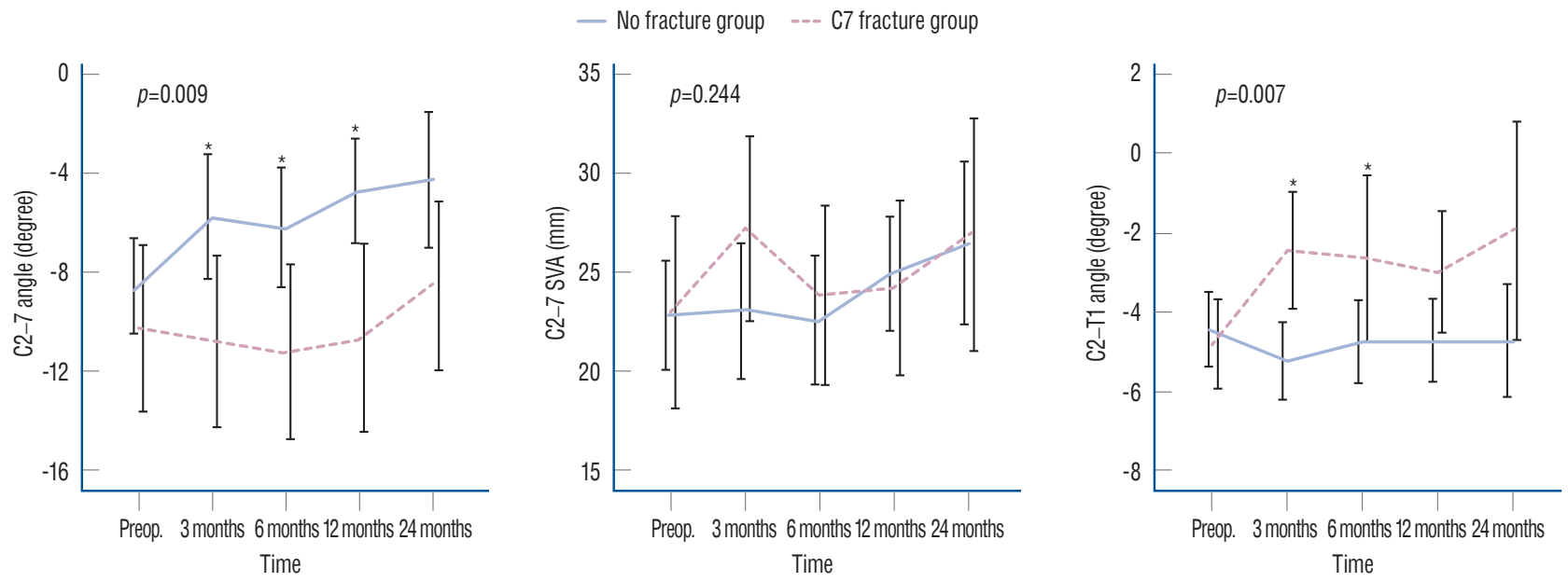

Fig. 4. Plots depicting the changes in the radiological outcome. The $\mathrm{C} 2-7$ and $\mathrm{C} 7-\mathrm{T} 1$ angles changed in different ways postoperatively, while the $\mathrm{C} 2-7$ SVA was similarly maintained between the groups. The asterisk indicates the presence of a statistically significant difference between groups. The negative value indicates a lordotic curvature. *Indicates the presence of significant statistical difference between the groups at the time point. SVA : sagittal vertical axis, Preop. : preoperative.

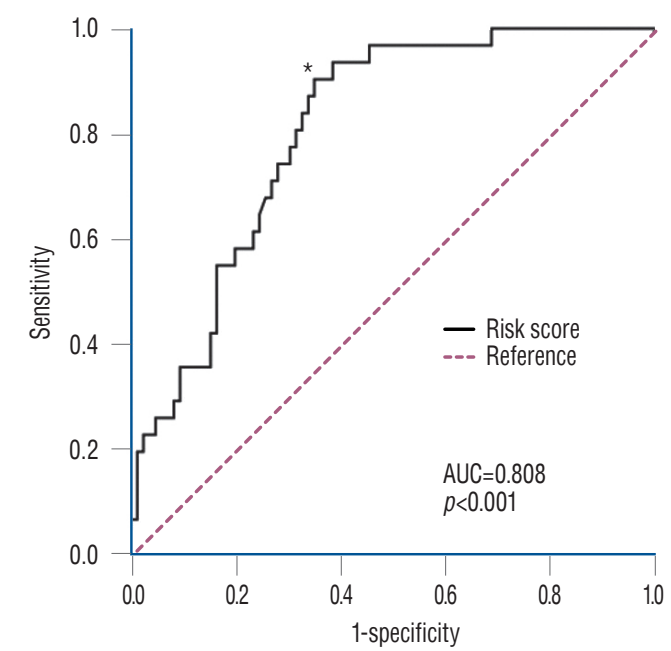

Fig. 5. ROC curve showing that the risk score can predict C7 laminar fracture with optimal sensitivity and false-positive rate (1-specificity). The asterisk indicates the risk score cutoff value of $167.9 \%$. ${ }^{*}$ Cut point. AUC : area under the curve.

\section{Risk factor evaluation}

From the univariate analysis, sex $(p=0.879)$, diagnosis $(p=0.287)$, shape of preoperative cervical curvature $(p=0.932)$, preoperative C2 -7 Cobb' angle ( $p=0.561)$, C7 SVA $(p=0.510)$, bone quality ( $p=0.386)$ and width of laminectomy $(p=0.136)$ were not significantly different between the groups. However, the length $(p<0.001)$ and depth $(p<0.001)$ of laminectomy were significantly related to $\mathrm{C} 7$ laminar fracture. Multivariate analysis using logistic regression showed that both depth $(p=0.002$; odds ratio $[\mathrm{OR}], 1.08 ; 95 \%$ confidence interval [CI], 1.03-1.13) and length ( $p=0.009$; OR, 1.03; 95\% CI, 1.01-1.05) were significantly related to $\mathrm{C} 7$ laminar fracture. Using the $\mathrm{OR}$, the risk of fracture was scored as follows : Risk score $=1.08 \times$ depth $(\%)+$ $1.03 \times$ length $(\%)$.

Receiver operating characteristic curve analysis was then performed with the risk score to determine the safety margin of C7 dome-like laminectomy with optimal sensitivity and specificity. The risk score showed adequate statistical strength in predicting C7 laminar fractures (Fig. 5); a risk score larger than $167.9(\%)$ demonstrated 'good' reliability (area under the curve, 0.81 ) in predicting C7 laminar fractures with a sensitivity of $90.3 \%$ and a specificity of $65.1 \%{ }^{16)}$. No fracture was found in patients who had a 'depth' of less than $45 \%$ of the posterior height of the $\mathrm{C} 7$ vertebral body, and only one fracture occurred in patients who had a 'length' of less than $75 \%$ of the posterior height of the $\mathrm{C} 7$ vertebral body.

\section{DISCUSSION}

To the best of our knowledge, there have been few literature reports of C7 dome-like laminectomy, although it has been performed in several institutes as an adjuvant procedure to routine cervical expansile laminoplasty ${ }^{8,11}$. Of course, there is no consensus or available information about the indication or decompression capacity of the procedure. We believe that $\mathrm{C} 7$ 
dome-like laminectomy cannot be substituted for C7 expansile laminoplasty or laminectomy because its decompression capacity would be limited compared to the other procedures. Therefore, we selectively adopted this procedure in cases where dorsal cord compression was expected by spinal cord shifting after surgery ${ }^{12)}$ or when stenosis was limited to the upper part of the C7 body level. Further research is needed on the decompression capacity or indication of C7 dome-like laminectomy.

The mechanism of the fracture has not yet been proven. However, there were few patients who experienced and reported a cracking sound and the simultaneous development of sudden neck pain when they extended their necks. Based on this finding, we speculated that mechanical stress was imposed on the $\mathrm{C} 7$ spinous process by the $\mathrm{T} 1$ spinous process; neck extension could be the cause. Tensile force imposed on the C7 spinous process transmitted by undisrupted extensor muscles and the nuchal ligament could be another considerable cause. Further study is necessary to clarify the exact cause.

\section{Clinical outcome}

C7 laminectomy has been known to affect the development of postoperative neck pain and cervical kyphosis. Biomechanically, the presence of C7 laminar fracture can be considered similar to the C7 laminectomy state, as fractured C7 lamina cannot function as anchoring points to the neck extensor muscles and ligaments. Considering that C7 laminectomy is closely related to increased neck pain and the development of kyphosis ${ }^{11,19)}$, it is plausible that patients with C7 laminar fractures may suffer from increased neck pain or cervical curvature changes. Unlike the C7 laminectomy state, of course, the C7 laminar fracture can be healed, and C7 may function again as an anchoring point once complete healing is achieved. Nevertheless, it is noticeable that the postoperative pain and disability scores were not different between the groups up to 2 years postoperatively. These results might be partially attributed to the relatively short time required for fracture healing. In our study, reunion was observed in more than $80 \%$ of cases within one year postoperatively. However, as C7 fracture seems to cause structural changes, it is not known how this will affect the long term.

\section{Radiological outcome}

It is noteworthy that the postoperative C2-7 angle of each group changed differently. The degree of cervical lordosis 'decreased' in the no fracture group and was relatively stationary in the C7 fracture group. Intuitively, decreased cervical lordosis may inversely cause an increase in C2-7 SVA. However, there was no difference in the C2-7 SVA between groups throughout the follow-up period. This result might be explained by the different ways in which the postoperative C7$\mathrm{T} 1$ angle changed in each group. In the C7 fracture group, the C7-T1 angle became more kyphotic, as seen in the results, while it remained relatively constant in the no fracture group. Based on this finding, it can be inferred that the change in the C2-7 angle compensates for the kyphotic change in the C7T1 angle to maintain cervical spine balance and horizontal gaze. A C2-7 SVA larger than $40 \mathrm{~mm}$ is known to be related to developmental axial neck pain, and horizontal gaze is an important factor affecting cervical spinal curvature ${ }^{1,3,6,13,20)}$.

The kyphotic change in the C7-T1 angle in the fracture group might have developed due to the loss of C7 anchoring function for extensor muscles and the nuchal ligament. Another possible reason for the kyphotic changes in C7-T1 in the fracture group may be related to the patients' behavioral changes for pain avoidance. The fractured laminae and spinous processes were invariably found to migrate inferiorly in the sagittal plane. Patients might have kept the lower cervical spine slightly kyphotic to avoid any collision of the fractured bone and extended upper segments to compensate for the segmental kyphosis made at the C7-T1 level. Thus, the long-term

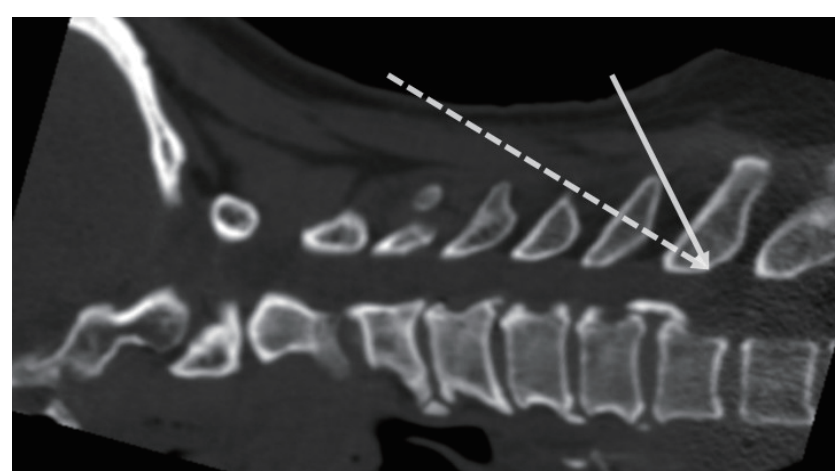

Fig. 6. A sufficient amount of dorsal space for the spinal cord could be achieved with a lesser extent of bone removal by shallowing the approach angle (dotted line arrow) for C7 dome-like laminectomy. The shallowing of the approach angle could be facilitated by resection or splitting of the $\mathrm{C} 6$ spinous process which makes the approach angle steeper (solid line arrow). 
effects of C7-T1 kyphotic changes need to be investigated.

\section{Risk factor evaluation}

The extent of bone removal in the sagittal plane, represented by 'depth' and 'length,' was the only risk factor for complications. Although we suggested specific formula and coefficient numbers, the point is to minimize the extent of bone removal while achieving appropriate decompression. An approach with a shallow angle can achieve an effective decompression, represented as 'depth,' while minimizing bone removal of the spinous process - the 'length' (Fig. 6). However, the spinous process of C6 may hinder the surgical corridor, which can maximize effective decompression. In this situation, a spinous process splitting approach or resection of the C6 spinous process prior to $\mathrm{C} 7$ dome-like laminectomy, which the authors have adopted in practice, could help shallow the approach angle. Similarly, considering the geometry of the C7 lamina in the mid-sagittal plane, C7 dome-like laminectomy would be more beneficial to patients with a high $\mathrm{C} 7$ slope or greater lordotic cervical curvature because more space dorsal to the spinal cord can be secured in the sagittal plane with the same amount of bone removal.

\section{Limitation}

Although this study is the first to report a C7 laminar fracture as a complication of $\mathrm{C} 7$ dome-like laminectomy and its prognosis, there are a few limitations. First, there has not been any consensus or reported indication of $\mathrm{C} 7$ dome-like laminectomy as an adjunction of open door laminoplasty. In a situation where the decompressive capacity of C7 dome-like laminectomy seems to be limited compared to C7 laminoplasty, it is necessary to establish an indication for $\mathrm{C} 7$ domelike laminectomy first. Second, we used the Hounsfield unit to assess the bone quality instead of the bone mineral density because bone mineral density was indicated only for women more than 65 -year-old or men more than 70-year-old under the health insurance system. Although it has been suggested that the Hounsfield unit measured at the cervical or lumbar vertebrae were well correlated to the T-score of DEXA bone densitometry ${ }^{2,18,22)}$, still the Hounsfield unit measurement was not a gold standard. This might have underestimated the effect of the bone quality in the occurrence of the fracture. Finally, the patient group consisted of a single ethnicity and race. It is not clear that the suggested safety margin could be applied to other races, which may have different physical features.

\section{CONCLUSION}

C7 laminar fracture could develop as a complication of C7 dome-like laminectomy in the early postoperative period. The extent of bone removal in the sagittal plane was related to this complication, and the risk can be estimated by the suggested formula. Therefore, care should be taken not to excessively remove the $\mathrm{C} 7$ lamina and spinous process even though the incidence of C7 fracture does not adversely affect clinical outcomes. Further study is warranted to clarify the long-term outcomes after this complication.

\section{CONFLICTS OF INTEREST}

No potential conflict of interest relevant to this article was reported.

\section{INFORMED CONSENT}

This type of study does not require informed consent.

\section{AUTHOR CONTRIBUTIONS}

\author{
Conceptualization : SHY, CHK \\ Data curation : SHY, YSK, YW \\ Formal analysis : SHY, CHL \\ Methodology: $\mathrm{CHK}$ \\ Project administration : SHY \\ Visualization : SHY \\ Writing - original draft : SHY \\ Writing - review \& editing: CHK, CKC
}

\section{ORCID}

Seung Heon Yang https://orcid.org/0000-0001-9447-5223

Chi Heon Kim https://orcid.org/0000-0003-0497-1130 
Chang Hyun Lee

Young San Ko

Youngil Won

Chun Kee Chung

https://orcid.org/0000-0003-0134-2101

https://orcid.org/0000-0002-6668-0905

https://orcid.org/0000-0002-9639-0693

https://orcid.org/0000-0003-3485-2327

\section{References}

1. Ames CP, Smith JS, Eastlack R, Blaskiewicz DJ, Shaffrey Cl, Schwab F, et al. : Reliability assessment of a novel cervical spine deformity classification system. J Neurosurg Spine 23 : 673-683, 2015

2. Colantonio DF, Saxena SK, Vanier A, Rodkey D, Tintle S, Wagner SC : Cervical spine computed tomography hounsfield units accurately predict low bone mineral density of the femoral neck. Clin Spine Surg 33 : E58-E62, 2020

3. Diebo BG, Challier V, Henry JK, Oren JH, Spiegel MA, Vira S, et al. : Predicting cervical alignment required to maintain horizontal gaze based on global spinal alignment. Spine (Phila Pa 1976) 41 : 1795-1800, 2016

4. Fujimura $Y$, Nishi $Y$ : Atrophy of the nuchal muscle and change in cervical curvature after expansive open-door laminoplasty. Arch Orthop Trauma Surg 115 : 203-205, 1996

5. Hosono N, Sakaura H, Mukai Y, Fujii R, Yoshikawa H : C3-6 laminoplasty takes over C3-7 laminoplasty with significantly lower incidence of axial neck pain. Eur Spine J 15 : 1375-1379, 2006

6. Hyun SJ, Kim KJ, Jahng TA, Kim HJ : Clinical impact of T1 slope minus cervical lordosis after multilevel posterior cervical fusion surgery: a minimum 2-year follow up data. Spine (Phila Pa 1976) 42 : 1859-1864, 2017

7. Ishikawa M, Matsumoto M, Chiba K, Toyama Y, Kobayashi K : Longterm impact of atlantoaxial arthrodesis on the pediatric cervical spine. J Orthop Sci 14 : 274-278, 2009

8. Jung JM, Chung CK, Kim CH, Yang SH : Clinical and radiological outcomes of C3-C6 laminoplasty with C7 dome-like laminectomy. Interdiscip Neurosurg $15:$ 47-52, 2019

9. Kim CH, Chung CK, Choi Y, Kuo CC, Lee U, Yang SH, et al. : The efficacy of ultrasonic bone scalpel for unilateral cervical open-door laminoplasty: a randomized controlled trial. Neurosurgery $86: 825-834,2020$

10. Kim P, Murata H, Kurokawa R, Takaishi Y, Asakuno K, Kawamoto T : Myoarchitectonic spinolaminoplasty: efficacy in reconstituting the cervical musculature and preserving biomechanical function. J Neurosurg Spine 7 : 293-304, 2007
11. Kowatari K, Ueyama K, Sannohe A, Yamasaki Y : Preserving the C7 spinous process with its muscles attached: effect on axial symptoms after cervical laminoplasty. J Orthop Sci 14 : 279-284, 2009

12. Kudo H, Takeuchi K, Yokoyama T, Yamasaki Y, Wada K, Kumagai G, et al. : Severe C8 or T1 symptoms after cervical laminoplasty and related factors: are tere any differences between C3-C6 laminoplasty and C3C7 laminoplasty? Asian Spine J 13 : 592-600, 2019

13. Lafage $R$, Challier V, Liabaud B, Vira S, Ferrero E, Diebo BG, et al. : Natural head posture in the setting of sagittal spinal deformity: validation of chin-brow vertical angle, slope of line of sight, and McGregor's slope with health-related quality of life. Neurosurgery 79 : 108-115, 2016

14. Lee $\mathrm{S}$, Chung CK, Kim CH : Risk factor analysis of hinge fusion failure after plate-only open-door laminoplasty. Global Spine J 5 : 9-16, 2015

15. Meena RK, Gurjar HK, Singh S, Aggarwal D : Absence of axis (C2) posterior elements leading to C2-C3 instability and myelopathy in young adults. Neurol India 67 : 318-321, 2019

16. Muller MP, Tomlinson G, Marrie TJ, Tang P, McGeer A, Low DE, et al. : Can routine laboratory tests discriminate between severe acute respiratory syndrome and other causes of community-acquired pneumonia? Clin Infect Dis 40 : 1079-1086, 2005

17. Ono A, Tonosaki Y, Numasawa T, Wada K, Yamasaki Y, Tanaka T, et al. : The relationship between the anatomy of the nuchal ligament and postoperative axial pain after cervical laminoplasty: cadaver and clinical study. Spine (Phila Pa 1976) 37 : E1607-E1613, 2012

18. Schreiber JJ, Anderson PA, Rosas HG, Buchholz AL, Au AG : Hounsfield units for assessing bone mineral density and strength: a tool for osteoporosis management. J Bone Joint Surg Am 93 : 1057-1063, 2011

19. Takeuchi K, Yokoyama T, Aburakawa S, Saito A, Numasawa T, Iwasaki T, et al. : Axial symptoms after cervical laminoplasty with C3 laminectomy compared with conventional C3-C7 laminoplasty: a modified laminoplasty preserving the semispinalis cervicis inserted into axis. Spine (Phila Pa 1976) 30 : 2544-2549, 2005

20. Tang JA, Scheer JK, Smith JS, Deviren V, Bess S, Hart RA, et al. : The impact of standing regional cervical sagittal alignment on outcomes in posterior cervical fusion surgery. Neurosurgery 71 : 662-669; discussion 669, 2012

21. Watanabe M, Sakai D, Yamamoto Y, Iwashina T, Sato M, Mochida J : Upper cervical spinal cord tumors: review of 13 cases. J Orthop Sci 14 : 175-181, 2009

22. Zaidi Q, Danisa OA, Cheng W : Measurement techniques and utility of hounsfield unit values for assessment of bone quality prior to spinal instrumentation: a review of current literature. Spine (Phila Pa 1976) 44 : E239-E244, 2019 